\title{
A Mulher que faz os caminhos Judeus-cristãos
}

Lina Boff - professora emérita da PUC-Rio

\section{Partindo da nossa realidade}

Como se apresentam tais caminhos nesse momento histórico? Partamos da realidade de hoje: de Norte a Sul do Brasil católico, nosso povo vive como experiência de fé e de aprofundamento dessa fé, datas que celebram acontecimentos marcados pela presença feminina de uma Mulher - Maria de Nazaré, judia como todas as outras de seu tempo, esposa de José da descendência de Davi, segundo as Sagradas Escrituras e Mãe do Messias que Israel esperava como Libertador e Salvador de seu povo.

No Brasil, chamamos este ano de Ano Mariano pelo fato de celebrarmos datas referentes a esta Mulher que fez e continua fazendo os caminhos do Cristianismo junto com os povos das diferentes culturas e de diferentes ritos religiosos de culto e veneração. Celebramos neste ano Maria de Nazaré com estes nomes:

@ Nossa Senhora da Conceição Aparecida em seu terceiro Centenário do Encontro da Santa nas águas do Rio Paraíba

@ Nossa Senhora de Fátima-Portugal em seu primeiro centenário das aparições

@ A primeira década da Conferência Episcopal Latino-americana e Caribenha que também fala desta Mulher - Maria de Nazaré - nos caminhos do cristianismo vivido pelos povos do nosso Continente.

As três datas celebrativas atualizam a presença de Maria de Nazaré ao longo dos milênios e séculos da pregação deixada por Jesus. As pessoas que o seguiram e creram na sua mensagem, apresentaram a Mãe do pregador Jesus como simples mulher judia de seu tempo. É o que vamos ver.

\section{Maria de Nazaré nas comunidades apostólicas}

Todos sabemos que os autores dos quatro Evangelhos do Novo Testamento da Bíblia, foram escritos pelas comunidades de Marcos, Mateus, Lucas e João, o evangelista. Cada um deles, com suas comunidades, apresentam Maria de Nazaré uma mulher judia como todas as outras. Ela é a esposa de José, mãe de Jesus seu filho, vai ao Templo de Jerusalém uma vez por ano e cuida de seu filho e seu marido como todas as mulheres judias de seu tempo.

Seu filho Jesus, aos poucos vai sendo reconhecido como o Messias esperado pelo povo de Israel, segundo as palavras dos profetas. Maria de Nazaré é nomeada pela narrativa dos quatro evangelistas como uma mãe que se preocupa com o filho e o segue de longe na sua vida pública. Ela não entende bem o que Ele prega, mas o segue com sua parentela. 
Jesus tinha um Projeto a realizar: era o Projeto de pregar o Reino de Deus aqui na terra em vista daquele Reino que vamos de encontro depois desta vida. Como todas as outras pessoas, Maria vai entendendo aos poucos a pregação de Jesus. Precisa esclarecer ainda: ela é sempre nomeada em momentos em que se faz necessário explicar às pessoas ouvintes da pregação de Jesus, a origem e de qual família Jesus vinha ou era oriundo.

Maria de Nazaré, nestes e noutros casos da narrativa dos evangelistas, não é reconhecida como a Santa, a Bendita, a Mulher que aparece às crianças, como no caso de Fátima, aos pastorinhos, nem é vista como aquela que havia recebido a mensagem do Anjo ${ }^{1}$ Gabriel para ser a mãe do Salvador de toda a humanidade. Ninguém de seu tempo conhecia o passado da vida dessa mulher que se confundia com as outras. Era simplesmente a mãe de Jesus, como outras tantas mães judias que tinham filhos.

Esses fatos nos mostram as primeiríssimas sementes de um Cristianismo que ainda não tem este nome, mas esses fatos já falam dessas origens.

\section{Maria de Nazaré nos Padres da Igreja}

Nos primeiros séculos do Cristianismo, depois da ressurreição e ascensão de Jesus ao céu, surgiram os Padres que vinham da linhagem dos Apóstolos, como Inácio de Antioquia, Justino, o leigo filósofo e Irineu de Lion, só para falar do nome de alguns. Nas Cartas que eles escreviam às suas comunidades começaram a falar de Maria como mãe de Jesus que havia pregado o Reino de Deus, que fora julgado como traidor do povo de Israel, fora morto, mas que no Terceiro dia ressuscitara e continuava vivo no meio de nós pelo seu Espírito. Pois, esta sempre foi a pregação dos apóstolos e agora desses Padres que vêm na linhagem das testemunhas que conviveram com Jesus.

Consideramos esse tempo como a época em que aparecem, nos escritos da Patrística, as primeiríssimas sementes da fé mariana em que as comunidades de fé iniciam o culto à Mãe de Deus, culto mariano que vai culminar com uma verdade cristológica da fé, verdade que chamamos, na linguagem da Igreja Católica, de dogma².

A verdade de que Maria de Nazaré é Mãe de Deus começou a ser invocada e cultuada com este nome teve seu início nas comunidades de fé dos primeiros séculos do Cristianismo. Só muitos anos depois dessa experiência e de muitas discussões dos teólogos em torno desse assunto é que a fé das comunidades que cultuavam Maria de Nazaré como Mãe de Deus foi proclamada dogma.

O povo descobre, com sua fé, que Maria de Nazaré é a Mãe de Jesus, Filho de Deus e filho dela. Ele é Deus na sua humanidade e na sua divindade. Maria de Nazaré, a partir da

\footnotetext{
${ }^{1} \mathrm{O}$ Anjo na Bíblia é sempre a figura de Deus que se revela à pessoa escolhida por Ele para realizar uma missão aqui na terra. A missão de Maria era a de ser a Mãe do Filho de Deus - o Jesus histórico do qual estamos falando.

${ }^{2}$ A palavra dogma não é uma fórmula, mas é um valor que cria espaço vital e abre horizontes, desdobra e aprofunda a verdade de fé.
} 
experiência de fé das comunidades dos primeiros séculos, passa a ser cultuada e invocada ao longo dos séculos e hoje como a Mãe de Deus, que na língua grega é significa a Theotokos.

\section{Por que então tantas Nossas Senhoras?}

Com o processo da inculturação do Cristianismo vivido pela pregação de mulheres e homens que acreditaram na mensagem deixada por Jesus, Maria de Nazaré passou a ser conhecida nas diferentes comunidades de fé onde a cultura não era a mesma da Galileia e da Judeia. Mas a pregação do Cristianismo não se limitou a esta parte do continente, entrou em outras culturas. Desse modo, Maria de Nazaré passou a ser conhecida e cultuada de acordo com o ethos cultural daquele povo em que os primeiros cristãos pregavam a mensagem de Jesus.

É do processo de inculturação do Cristianismo, que Maria passa a entrar na devoção e no culto a ela dedicados, donde lhe vêm os mil nomes que as culturas dos diferentes povos lhe dão. Esse processo, porém, vem da pregação deixada por Jesus às mulheres e aos homens que o seguiram.

Hoje, por exemplo, quando falamos da mensagem deixada por Jesus, o Cristo da fé, Maria de Nazaré é apresentada como a Mulher que aponta para Jesus, seu filho e ao mesmo tempo Filho de Deus porque Ele é Deus como o Pai. Por que isso acontece? Pelo simples fato de que Maria de Nazaré seguiu Jesus como cada um de nós.

Como mãe aprendeu dele a não ser apenas mãe biológica, mas de pertencer a uma família maior e abrangente, que é a família da fé trazida pelo seu filho como Filho de Deus que veio nos mostrar o rosto misericordioso do Pai que é também nosso Pai que está nos céus.

Da pregação feita pelas mulheres e homens dos primeiros séculos do Cristianismo, a mãe de Jesus nunca deixará de ser sempre a mesma Maria de Nazaré. Mesmo que seja invocada com outros nomes, ela sempre será mãe de Jesus, Filho de Deus e filho dela. Foi e é esta a Maria apresentada pelos evangelistas, Marcos, Mateus, Lucas e João, o evangelista.

No Novo Testamento ela é Maria de Nazaré, como qualquer outra mulher judia. $\mathrm{Na}$ Patrística começa a ser apresentada àquelas primeiras comunidades como a mãe de Deus. E hoje ela toma o nome da cultura onde é conhecida pela pregação das mulheres e dos homens que falam da Boa Notícia trazida pelo Cristo da fé.

Pode-se afirmar que a caminhada de Maria de Nazaré chega ao seu coroamento no Cristo da fé trazido pela humilde serva do Senhor que se abriu à graça do Pai para que seu Filho Jesus tomasse a nossa natureza humana no Mistério da Encarnação. Nesse contexto Maria sempre aponta para os ensinamentos deixados por seu filho, e dos quais ela se tornou discípula-mãe. É exemplo e lição de discipulado para todas as pessoas que acreditam na mensagem de justiça, de misericórdia e de amor sem limites deixados por Jesus na Tradição, nas Sagradas Escrituras e na experiência de fé dos povos de todas as culturas. 


\section{Trazendo para o Ano Mariano}

As aparições de Fátima são uma mensagem que Cristo nos envia através de uma Mulher que fala com crianças da periferia. Ela deixa uma mensagem que a teologia interpreta como um jeito que Deus tem de se revelar e nos deixar uma mensagem. Esta mensagem aponta para os caminhos do bem, da justiça e da construção de sociedades humanas. Sociedades que tenham como prioridade o respeito pela criação do ser humano e de tudo o que ele precisa para viver com dignidade e realizar a mensagem deixada pelo Cristo da fé.

O encontro da Santa de Aparecida nas águas do Rio Paraíba mostra a secular escravidão em que vivia o povo brasileiro daquela época. Hoje, continua tão real e presente como "madroeira" Nacional do povo brasileiro, porque sempre esteve presente nos fatos históricos da nossa sofrida história do Brasil. Nesses momentos de conflito o povo se aproximou da Mãe Aparecida como irmã e companheira de caminhada para ser atendido em suas preces e súplicas.

E a celebração da Conferência dos Bispos da América Latina e Caribe, renova a nossa luta por nos tornar um povo livre e construtor da própria história para que se viva a vida de filhas e filhos de Deus. O bispo que esteve à frente na elaboração do Documento de Aparecida, é agora, o nosso papa e bispo Roma. Ele preside a vida de fé em Jesus Cristo, fala e prega a Verdade que nos liberta e é nosso Companheiro pelas estradas da vida.

\section{Concluindo este breve artigo}

Acabamos de apresentar um exemplo que inspira o modo com que se pode seguir os ensinamentos de Jesus deixados para todos os povos das diferentes culturas. Maria foi e é uma Mulher que avançou no caminho da fé aos poucos e foi aprendendo do seu jeito aquilo que seu filho ensinava ao povo.

Viveu sua vocação como mulher casada, como mãe e como amiga das mulheres de seu tempo. Frequentava o Templo de Jerusalém com o marido e o filho. Meditava no Mistério da vida sob os véus do cotidiano. O Deus Pai apresentado por Jesus seu filho, Ihe era familiar e ao mesmo tempo estranho. O lugar em que ela se encontrava com o Mistério do Divino era o simples cotidiano. Meditava e se perguntava sobre o significado de cada coisa que the acontecia e vivia no seu dia-a-dia.

A misteriosa alquimia que Maria utilizava para transfigurar sua vida era meditar amorosamente cada fato caído em seu coração como pérola preciosa sendo lapidada como joia espiritual enriquecedora de sua vida silenciosa e toda voltada para o Mistério do Divino.

\section{Referências para enriquecer sua leitura}

AA. VV. Imaculada, Maria do Povo, Maria de Deus. Petrópolis: Vozes, 2004

BOFF, Clodovis. Mariologia Social. O significado da Virgem para a sociedade de hoje. São Paulo: Paulus, 2006. 
--. Maria na cultura brasileira. Petrópolis: Vozes, 1995.

---. O cotidiano de Maria de Nazaré. São Paulo: Salesiana, 2003.

BOFF, Leonardo. O rosto materno de Deus. Ensaio interdisciplinar sobre o feminino e as suas formas religiosas. Petrópolis: Vozes, 1979.

---. A Ave-Maria. O feminino e o Espírito Santo. Petrópolis: Vozes, 2002.

BOFF, Lina. Maria na vida do povo. Ensaios de mariologia na ótica latino-americana e caribenha. São Paulo: Paulus, 2002.

---. Mariologia. Interpelações para a vida e para a fé, Petrópolis, Vozes, 2007.

---. Como tudo começou com Maria de Nazaré. Rio de Janeiro: Letra Capital e Academia Marial, 2016.

---. Aparecida: 300 anos de romaria em prece. São Paulo: Paulinas, 2017.

MARTíN, Lutero. O Magnificat. Petrópolis: Vozes, 1968.

MURAD, Afonso. Toda de Deus e tão Humana, São Paulo: Siquem/Paulinas, 2004.

WILIAM, Francisco Miguel. Vida de Maria, Mãe de Jesus. Petrópolis: Vozes, 1940.

\section{Para refletir:}

1. A autora nos apresenta a trajetória de Maria e das primeiras comunidades. Enfim, a proclamação de Maria como Mãe de Deus brota da experiência das comunidades de fé dos primeiros séculos. Como você percebe essa experiência de encontro e reconhecimento de Maria nos dias de hoje?

2. Se Maria é apenas uma pessoa, por que tantas Nossas Senhoras no Brasil e no mundo? 